\title{
Comparing Vector-host and SEIR models for Zika Virus Transmission
}

\author{
Puji Andayani ${ }^{1 *}$, Rizal Dian Azmi ${ }^{2}$, Lisa Risfana Sari ${ }^{3}$ \\ ${ }^{1}$ Department of Informatics, Universitas Internasional Semen Indonesia, Gresik, Indonesia \\ ${ }^{2}$ Department of Mathematics Education, University of Muhammadiyah Malang, Malang, Indonesia \\ ${ }^{3}$ Department of Management, Universitas Internasional Semen Indonesia, Gresik, Indonesia
}

\begin{abstract}
Some mathematical models to describe Zika virus transmissions have been analyzed. In this study, we construct two models of Zika virus transmission. The first one is the vector-host model. It considers the human population as host and mosquito's population as the vector. The second model is where there is only infected human population who act as transmitter without the existence of infected mosquitoes in the population. The impact of modeling assumption of Zika virus is studied by analyzed the reproduction number using Next Generation Matrix (NGM) method. Formerly, we compare the dynamics of the two models by interpreting the reproduction number of each model. Biologically, the two models cause a similar effect. If the reproduction number is less than one, then the disease is extinct. Otherwise, an endemic condition exists. The numerical simulation also used to explain the comparison of two models. The recovery and the transmission period are solved to compare these two cases.
\end{abstract}

Keywords: comparison, mathematical model, reproduction number, SEIR, Zika Virus.

\section{INTRODUCTION}

Zika virus is spread by mosquito bites which are Aedes aegypti and Ae. albopictus. It is also transmitted by sexual intercourse, and blood transfusion. Zika virus can be moved horizontally from a pregnant woman to her embryo. It causes a certain birth defect when it is infected pregnant women. Based on the latest update of CDC, Zika virus also can be transported to animals, namely monkeys and apes. No vaccine or medicine exists to prevent Zika virus [5].

Zika virus will become a serious problem when it infects pregnant women because it relates to congenital abnormalities including microcephaly, spontaneous abortion, and intrauterine growth restriction. Further, for nonpregnant women also for men, it causes GuillainBarre Syndrome. Transmission between humans and Ae. Aegyepti mosquitoes can increase the epidemics of Zika [1,3].

The CDC is reporting that Zika virus has been transmitted around the United States. Women and men, who travel to the United States, should be aware and follow steps to prevent mosquito bites to reduce their risk for Zika. For at least 6 months, men should using a condom or not having sex, and women also using a condom or

\footnotetext{
* Correspondence address:

Puji Andayani

Email : puji.andayani@uisi.ac.id

Address : Dept. Informatics, Universitas Internasional Semen Indonesia, Jl Veteran, Kompleks PT Semen Indonesia, Gresik.
}

not having sex for at least 2 months from August 29, 2017 [6].

Some mathematical models have been studied Zika virus epidemiology, also the vectorhost Zika transmission. Andayani analyzed the dynamics of Zika virus transmission with the vector-host model, which is SIR model of host and $\mathrm{SI}$ model for the vector [8]. The existence of R_0 (reproduction number) is used to identify the stability of the system. If $R \_0<1$ the DFE is stable locally and globally, otherwise the END is stable locally and globally. It is appropriate with CDC report, which is Zika does not cause death [8].

Pandey [4] investigated the comparison of vector-host and SIR model of dengue transmission and fit the models to data for validates. Then estimate the parameter by using Markov chain Monte Carlo (MCMC). Jafaruddin [2] constructed a host-vector for West Nile Virus transmission model in mosquito chicken populations. The dynamics analysis investigated by interpreting the reproduction number. In this paper, we investigate the impact of modeling assumptions on epidemiological for Zika Virus by using reproduction number interpretation. In the final section, the two models are compared by numerical simulations.

\section{MATHEMATICAL MODELS}

We construct two mathematical models of Zika virus transmission. First, in which the mosquito is existed in the area and spread Zika virus to human, it is a vector-host model. Other 
we assume there exist mosquito, and the human is infected by traveling from Zika transmits area.

\section{Vector-Host Model}

The vector-host model of Zika virus transmission represented by the following nonlinear differential equations:

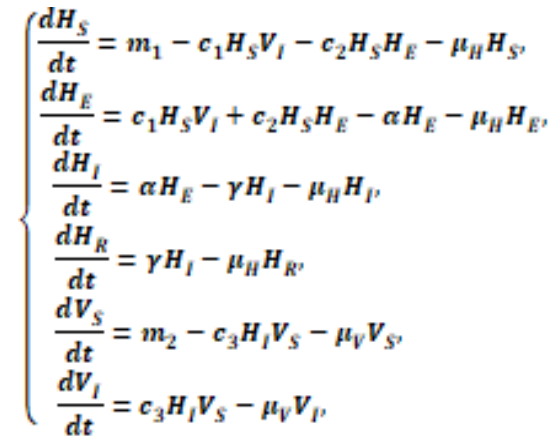

where $H_{S^{s}} H_{E^{s}} H_{I^{s}} H_{R^{s}} V_{S_{s}} V_{I}$ stand for suspected human, exposed human, infected human, recovery human, suspected vector, and infected vector, respectively. In this case, we assume all parameters are positives. The parameter $m_{1}$ denotes the growth rate of the human; $m_{2}$ denote the growth rate of mosquito. Then $c_{1}$ denote the rate of direct transmission of the virus, $c_{2}$ denote the rate of transmission from exposed to a suspected human, and $c_{a}$ denote the rate of transmission from infected human to suspected vector. The parameter $\alpha$ is per capita infection rate of the exposed human, and $\gamma$ is per capita recovery rate of the infected human. The parameter $\mu_{H}$ means the death rate of human, and $\mu_{V}$ means the death rate of the vector (mosquito).

Biologically, the trajectories of the system (1) can be explain by identified the reproduction number of the system. The reproduction number of system (1) can be compute by using Next Generation Matrix (NGM) method [1], which is

$$
R_{B}=\frac{\left(\mu_{Y}{ }^{2} c_{2}\left(\mu_{H}+\gamma\right)+\alpha c_{1} c_{3} m_{2}\right) m_{1}}{\mu_{H F} \mu_{Y}{ }^{2}\left(\mu_{H}+\alpha\right)\left(\mu_{H}+\gamma\right)} .
$$

Based on equation 2, it identified that all parameters influenced the value of reproduction number. The rate of direct transmission of $\operatorname{virus}\left(c_{1}\right)$, the rate of transmission from exposed to a suspected human, and the rate of transmission from infected human to suspected vector $\left(c_{a}\right)$ which causes the mosquitoes infecting virus, increase the value of reproduction number. When the parameters of the rate of direct transmission of virus, the rate of transmission from exposed to suspected human, and the rate of transmission from infected human to suspected vector are increasing, then the reproduction number also increases. In addition, when the growth rate of human $\left(m_{1}\right)$ and the growth rate of mosquito $\left(m_{2}\right)$ are increasing, then the reproduction number also increase. It is suitable for real cases. If the number of population is greater, then the interaction between human and mosquito will be greater than usual. This factor causes advances the spread of infection.

\section{SEIR Model}

The SEIR model of Zika virus transmission represent by the following nonlinear differential equations:

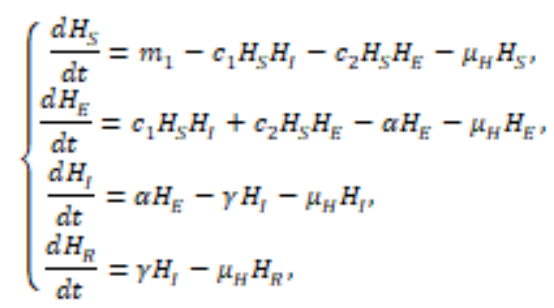

where $H_{S^{\prime}} H_{E^{x}} H_{I^{x}} H_{R^{x}}$ stand for suspected human, exposed human, infected human, recovery human, respectively. The parameter $m_{1}$ denotes the growth rate of the human. The parameter $c_{1}$ means the rate of direct transmission of virus from infected human, and $c_{2}$ denote the rate of transmission from exposed to suspected human. The parameter $\alpha$ denotes infection rate of the exposed human, $\gamma$ denote recovery rate of the infected human, and $\mu_{H}$ means the death rate of the human.

The interpretation of the system (3) is determined by analyze the reproduction number $R_{0}$, which is computed by using Next Generation Matrix (NGM) method. The following equation is the reproduction number for system (3), such as

$$
R_{0}=\frac{\left(\mu_{H} c_{2}+\alpha c_{1}+c_{2} \gamma\right) m_{1}}{\mu_{H}\left(\mu_{H H}+\alpha\right)\left(\mu_{H}+\gamma\right)} .
$$

All parameters of the SEIR model are influenced with the value of reproduction number. The rate of interaction among human, which is the rate of infected and suspected human, and the rate of transmission is from exposed to a suspected human, are directly proportional with reproduction number. It is due to the more frequent interaction between human and mosquito then the chances of infection become greater. Moreover, the number of 
infection spread can be influenced by the number of population which contact with the growth rate of the human. When the growth rate of the human is increasing, then the probability of interaction which is caused infection also increased.

\section{SIMULATION AND RESULTS}

The simulation of these systems also needs to see the trajectory of the system. In this study the simulation of the system are analyzed using software Matlab. At the first case, we choose the value of parameters are

$c_{1}=0.1 ; c_{2}=0.1 ; c_{3}=0.01 ; a=0.1 ; \mu_{f f}=m_{1}=$ $0.00004^{*} \mu_{Y}=m_{2}=0.05^{s}$

and $\gamma=0.3$. Based on the chosen parameter we have $R_{\text {DYW }}>1$ and $R_{\text {DSEF }}>1$. Then the simulation of the system (1) and (3) are shown by the following :

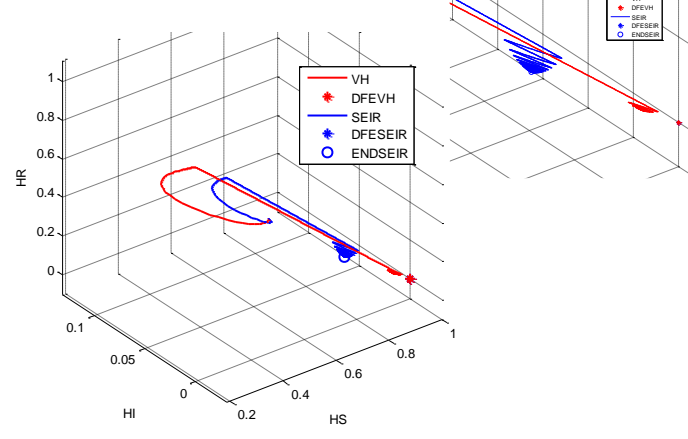

Figure 1. The Simulation of Case 1

The second case of these simulations is when the reproduction numbers are less than one. Then choose the parameter values are $c_{1}=0.1 s c_{2}=0.01 ; c_{3}=0.1 ; \alpha=0.09 ; \mu_{p f}=m_{1}=$ $0.00004^{s} \mu_{Y}=m_{2}=0.05$;

and $y=0.3$. Then we have the following simulation:

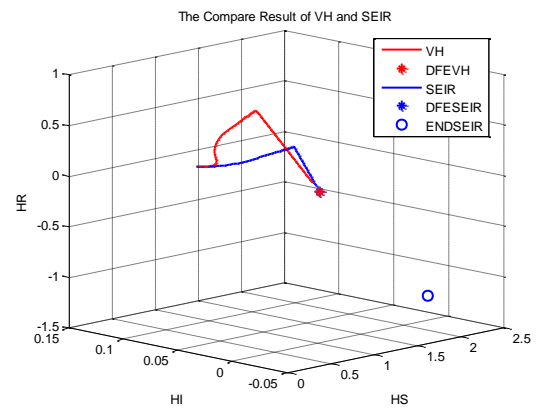

Figure 2. The Simulation of Case 2

Based on figure 2, we can see that by using the parameter values on cases 2 the trajectories of the system (1) and (3) are tends to the disease free equilibrium. Biologically this case means according to that parameters of the case 2 , the populations will be free from Zika virus.

The third case is when $R_{a y m}<1$ and $R_{\text {Miser }}>1$. Then choose the parameter values are $c_{1}=0.1 ; c_{2}=0.01 ; c_{3}=0.2 s a=0.1_{j} \mu_{f f}=m_{1}=$ $0.00004 ; \mu_{Y}=m_{2}=0.05 s$

and $Y=0.3$. The simulation of the system (1) and (3) are in the Figure 3.

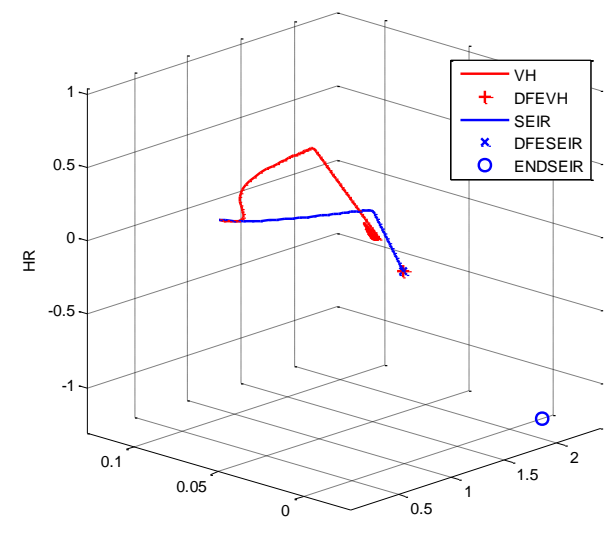

Figure 3. The simulation of case 3

By the figure 3 we can see the trajectories of system (1) will tends to endemic and the system (3) will tends to disease free. It is consistent with the previous simulation which is epidemic Zika virus in case $\boldsymbol{R}_{0}>1$, otherwise the Zika virus will be free in case $\boldsymbol{R}_{0}<1$.

Finally, the comparison of the vector-host and SEIR models are describe by the following table:

Table 1. The Comparison of Vector-Host and SEIR Models

\begin{tabular}{cccc}
\hline $\begin{array}{c}\text { Reproducti } \\
\text { on number }\end{array}$ & Characteristic & $\begin{array}{c}\text { Vector- } \\
\text { host } \\
\text { model } \\
\text { (days) }\end{array}$ & $\begin{array}{c}\text { SEIR } \\
\text { model } \\
\text { (days) }\end{array}$ \\
\hline$R_{0}>1$ & Recovery time & 32 & 20 \\
$R_{0}<1$ & Epidemic & 21 & 31 \\
& Recovery time & 25 & 40 \\
\hline
\end{tabular}

\section{CONCLUSION}

According to the previous explanation, we have the following conclusion.

1) In generally, Zika virus will be free in the area when the reproduction number is less than one. Otherwise, the Zika virus will epidemic.

2) If reproduction number is greater than one, the recovery time of vector-host model is $\mathbf{3 2}$ days and the SEIR model is 20 days. Moreover, the Zika virus will be epidemic in the area in 21 days for the vector-host model, and 31 days in the SEIR model. 
3) If reproduction number is less than one, the recovery time of vector-host model is 25 days and the SEIR model is 40 days. Additionally, the Zika virus will be epidemic in the area in 20 days for the vector-host model, and 40 days in the SEIR model.

\section{ACKNOWLEDGEMENT}

The author expressed a big appreciation to Directorate Research and dan Communiry Service (DRPM), Directorate General of Research and Development Strengthening, Ministry of Research, Technology and Higher Education for the funding support. The author also would like a big thanks to Research and Human Responsibility Institute of Universitas International Semen Indonesia for the greatest support.

\section{REFERENCES}

[1] Van den Driessche, P., W. James. 2002. Reproduction numbers and sub-threshold endemic equilibria for compartmental models of disease transmission. Math. Biosci. 180. 29-48.

[2] Jafaruddin, J.W. Puspita, N. Nuraini, E. Soewono. 2014. Dynamical model for transmission of West Nile Virus in chickenmosquito interaction. J. Math. Fund. Sci. 46. 290-300.

[3] Mysorekar, I.U., M.S. Diamond. 2016. Modeling zika virus infection in pregnancy. N. Engl. J. Med. 375. 481-484.

[4] Pandey, A., A. Mubayi, J. Medlock. 2013. Comparing vector-host and SIR models for dengue transmission. Math. Biosci. 246. 252-259.

[5] U.S. Department of Health and Human Services. 2016. Center for Disease Control and Prevention. Available at: https://www.cdc.gov/zika/healtheffects/ind ex.html.

[6] U.S. Department of Health and Human Services. 2017. Center for Disease Control and Prevention. Available at: https://www.cdc.gov/zika/geo/index.html.

[7] U.S. Department of Health and Human Services. 2017. Center for Disease Control and Prevention. Availeble at: https://www.cdc.gov/zika/transmission/ind ex.html.

[8] U.S. Department of Health and Human Services. 2017. Center for Disease Control and Prevention. Available at: https://www.cdc.gov/zika/transmission/ind ex.html. 